\title{
E-Mail: Connections, Contexts, and Another Space
}

\author{
Terry Caesar
}

Everyone knows a story of someone who pressed the "send" key too soon, and thereby (blush) unintentionally transmitted a personal e-mail response to a list or a listserv rather than an individual. Two theses about e-mail: it remains too fast a technology of communication and it continually confounds the boundary between the categories of the public and the private. On the other hand, though, everyone who e-mails knows how a particularly important or urgent message often must be supplemented by a phone call. Two more theses about e-mail: it does not communicate fast enough, and it remains well to the private side of the divide between public and private technologies of communication.

So it goes about the technology. There seems to be too much to claim about such a vast, intricate phenomenon, even its contradictions. The world has been defined as more than the sum of everything that could be said about it. E-mail today is very much like the world (as well as now constituting one definition of the world, around which is being woven, according to William Mitchell, an increasingly dense, multilayered cocoon of antennas, network access points, relay points, and channels [Mitchell 2003: 55]). It is not easy to extricate e-mail—including listservs, discussion groups, and chat rooms as well as one-to-one communication-from this world. Furthermore, any single e-practice is finally inseparable, if only technically, from the entire aggregate of the Internet. It is not that there is too much e-mail. It is that "e-mail" stands for too much.

For example, Ben Agger mentions an "Internet billionaire" who returned from a recent trip to have 2,230 e-mails awaiting him. He proceeds to wonder about what exactly an adequate model of reading (not to say writing) could be before such a number (Agger 2004: 113-14). And yet there are undoubtedly thousands or even millions of people who count themselves fortunate to receive one e-mail message on any given day, according to the old sentimental model of a letter in the mailbox. One world can comprehend both groups of people. (As well, the continual slippage or transformation of e-mail into mail delivered by the post office.) But can one practice/comprehend both? Or rather, one technology — to Mitchell, ultimately comprehending everything from prenatal imaging to posthumous digital traces - which enables a multiplicity of practices?

One explanatory strategy: simply convert the technology into the multiplicity. Hence, Agger, for example, speaking of the proliferation of "self" prefixes: "More than ever, we need to attend to self-assemblage, the ways in which people electronically create themselves in the figural, flickering, spectral world of the Internet" (Agger 2004: 119). E-mail, in other words, is at once nothing less than one of those ways and nothing more than a convertible term into the sum of all of those ways. Maybe so. My own argument, however, will question the larger terms though which virtual selfhood is made manifest through e-mail, which I will take to represent the best, most explicit manifestation of "the continuous and irrepressible presence of subjective movements" within the Internet.

I take this last phrasing from Michael Hardt and Antonio Negri, who are not at this moment specifically discussing the Internet but instead the "non-place" of power, "the site where the hybrid control functions of Empire" is exercised (Hardt and Negri 2000: 319). E-mail represents to them a signal instance of this site, whose spatial as well as temporal displacements constitute one especially preeminent way in which power is at once constituted by "sovereignty" as well as expressed by each individual as "subjective. "On the latter point, Mitchell gives precisely the 
right note: "I am part of the networks, and the networks are part of me. I show up in the directories. I am visible to Google. I link, therefore I am" (Mitchell 2003: 62). You have to be part of the networks in order to e-mail while at the same time they have to be part of you. But you do not have to be so sanguine about it and you may even be skeptical of such happy reciprocity.

Hardt and Negri go on to speak of "today's imperial constitution" as conceivable "in the form of a rhizomatic and universal communication network in which relations are established to and from all its points or nodes. " On the one hand, they continue, "the network formally allows all possible subjects in a web of relations to be present simultaneously, but on the other hand, the network itself is a real and proper non-place" (Hardt and Negri 2000: 319-20). Where Mitchell cavorts in this non-place site of miniaturized, digitalized, dematerialized, delocalized connectivity Hardt and Negri merely conclude that its constitution must be a contested site. My own argument will be to try to restore something of the terms of the contest, through focusing on e-mail as a subjective movement of a particular kind, coalescing around three areas: community, body, and code.

In order to understand both our bodies and our various networks, " [w] will do better, " Mitchell states at one point, "to take the unit of subjectivity, and of survival, to be the biological individual plus its extensions and interconnections” (Mitchell 2003: 39). E-mail is of course e-mail, in one respect, because it constitutes an acting-out of this proposition; no one emails as it were biologically. And yet no one survives electronically in a non-place. In the following discussion, I will strive to restore materiality to this place, which functions as if successful access to its potential connections ultimately represents all that need be said about it.

It does not. Once electronically connected, links are not only gained. Other links are left behind, neglected, or ignored. The subjective moment of e-mail is won at some cost, for through it society suffers its own displacement, the body its own alienation, and individual identity its own rewriting according to code. These consequences are not to be wholly lamented. As a medium for interaction and transaction, e-mail is a remarkable fact, which has changed the range, the ease, and even the very nature of human communication. Just because it is so remarkable, though, it needs to be subjected to a more strenuous critique. What is the status of the subjective in electronic communications? Where is it located? What remain its constraints? Finally, what are its protocols? These are the questions which I want to explore, partly in personal terms they require.

\section{Community}

One day while teaching in Japan I was surfing the Internet. I chanced upon a site that mentioned a conference in Asia on language. To my surprise, the conference included a paper by a woman who shared my family name. Even more surprising, she taught in South Korea! Could she be a relative? I have hardly met anyone in my whole life named "Caesar. "So, what the hell, I decided to e-mail the woman and ask her if by some chance we could be related. Perhaps it would not have mattered where she lived, although on this occasion our geographic proximity did seem to persuade me even more to write. The conference site gave her e-mail address.

The woman was outraged to reply. Who was I, exactly? How did I get her address? Shocked, I tried to explain once more who I was, and how I got gotten her address from a public space, available to anyone who logged on to the Internet. The woman responded quickly. She did not know who I was, but she was sure of one thing: I was harassing her. She demanded that I cease at once trying to communicate. This time I was more amazed than shocked. Didn't the woman know anything about e-mail? Immediate contact, more oral than written, heedless of context, and so on? How was this possible not to understand that e-mail is different?

But of course such a reaction not only remains possible but is in fact positively constitutive of e-mail community. Through e-mail, contact can now be made between or among any number of individuals on earth, at least technically. Yet this does not make them a "community, " not even when we attempt in each case to unpack the circumstances (professional in my above case) that enable the contact in the first place. First, the contact is fraught with assumptions and conventions, just as all contacts are. Discussions of e-mail often ignore these, as if the technology either takes care of assumptions all of itself or else comes with a tacit agreement to set conventions aside in the interests of efficiency and the sheer wonder of connectivity.

Evelyn Nien-ming Ch'ien, for example, compares the community formation of the Internet to periodicals, by means of a common energizing of the vernacular, only more so. "Language also functions differently on the Internet; it is more active and alive, since users can be instant text-messaging or emailing a response quickly" (Ch'ien 
2004: 284). She goes on to note that formal language and even grammar can be dispensed with and how "e-language cultures do not encourage monoglot reading publics; they encourage linguistic individualism" (Ch'ien 2004: 286). Therefore, Internet exchanges are more like conversations and "Internet community is more tangible and effable" (Ch'ien 2004: 286). Never once does Ch'ien question whether in fact the technology fosters a kind of contact, not to say community, so facile as to be ephemeral.

Not all e-contact fosters community, although arguably most communication happens in the first place within some larger enabling conditions, on the model of a professional specialization (Linguistics, String Theory, Legal Studies) or a special interest group (dog breeds, movie stars, computer games). In fact, one could easily argue that even discussion groups do not constitute "communities" in a very searching or comprehensive way, since members are free to leave at any time (technical instructions on how to do so are as important as instructions about how to join) and all abide under conditions of such constraint (if only because of the danger of "flame wars") that community boundaries are scarcely tested, much less explored. Common interests, in other words, are not at all the same thing as common values; interests are purely cognitive in nature, and do not claim to govern actions either as determinatively or cohesively as values.

Take the instance of humor. One distinct, significant function of e-mail continues to be the dissemination of humorB-anecdotes, stories lifted from public media, jokes. To whom? Virtually anybody. It is so easy through e-mail to copy a joke and send it to a few like-minded people as well as one's usual correspondents, that often one forgets the joke a few minutes after hitting "send." (Or else eventually receives the joke back, through the same spontaneous, scattershot logic by which it was transmitted.) Why send the joke at all? In a sense, to gesture to, if not create, an instant "community" of people who take some pleasure in the humor, as well as perhaps in themselves being so constituted, however ephemerally.

Yet, although of course the communication of a joke can consolidate an already-established (or wired) group of people, the transmission alone creates no more than the fantasy of a community. Much e-mail abets this fantasy. A commonly agreed-upon narrative of "community" persists - under whose auspices connectivity proceedsborrowed from the social world away from the computer screen and the keyboard. On the contrary, though, connectivity no more necessarily leads to community than the mere fact of communication does. A better analogy for e-community has to do with the transitory one created by jokes rather than the more fixed one based upon the manifold subjects of discussion groups.

And a better way of understanding the function of any sort of "community" in e-discourse is to claim that it is so constituted on the basis of a single rationale: escape from actual communities in three-dimensional space and real time. In fact, e-mail abides as an important way of recuperating what actual communities lack: sympathetic others, entertainment opportunities, stimulating conversation. It also continues as a significant way of transposing the energies of the workplace, and therefore increasingly businesses attempt to restrict e-activity by making all communication official, and frequently having a disclaimer tag on each message posted by the server, to the effect that content is privileged, confidential, and may not be misused.

The remorselessly private register of such a tag contrasts with the happily public character of e-mail technology. (Or its celebrants_-for example, James Barksdale: "Open Internet softwear will change the whole communications paradigm. Organizations will tear down walls and have common Internet infrastructure running across all their systems” [Barksdale 1998: 98]. But what about erecting walls against private use?) In fact, the technology's very technical constituents have nothing "privileged" about them; all e-mail either can be retrieved from a computer's hard drive or be read via a server. Furthermore, e-mail can always be copied; its confidentiality is in this respect inherently unstable.

Finally, the fact that it can be "misused" perhaps comprises one of the primary pleasures of e-mail, whether receiving something originally sent to someone else, cutting and pasting from one message into a new one, or just emailing from work anyway, restrictions be damned. From the attempts of so many businesses, corporations, and institutions to restrict e-mail activity, we can understand two things about it. First, the notion of "community" it fosters cannot easily be willed into existence and restricted in scope. Indeed, there is something unregenerately private about e-mail, or at least heedless of official discursive regimes. Ch'ien is right about the linguistic individualism of e-language cultures. They take their values from the conditions of e-production - a sole individual, on line, rather than the conditions of e-reception - ten, twenty, hundreds or even thousands of others, on the basis of a single post. The values are the values of virtuality itself, which by definition cannot be grounded (or else it would be actual rather than virtual). 
Secondly, e-community continually seeks an actual-world supplement that either dissolves strictly discursive virtual bonds or transforms them into the more real, compelling relations of actual space and time. In a discussion of virtual community, after stressing the importance of "absorbing" new procedures and customs of any one, Howard Rheingold concludes with the following disclaimer: "Don't forget that telephones and face-to-face meetings are still appropriate ways to cement and extend the friendships you make on-line" (Rheingold 1998: 121). Undoubtedly this is true. But then the virtual community ceases to be virtual.

Discussions of the peculiar relatedness that e-mail makes possible continually ignore the logic of such disclaimers, as the notion of "community" suffers a slippage into the idea of friendship or the fact of family. "I have found that e-mail has helped me to strengthen relationships with members of my family who do not live near me," writes Barksdale (Barksdale 1998: 99). Again, undoubtedly true for many other people, and representative of one of the many social benefits of e-mail. But the creation of community is not one of them. E-community really resides to one side of the famous sociological distinction between Gemeinschaft and Gessellschaft, in some instances contracting to a condition resembling the intimacy of the one, at other instances expanding to something approximating the impersonality of the other, but in all instances relying on an analogy to the social world that cannot be fully realized in e-terms.

Mitchell would reply that e-terms are simply part of those of the world now, just as the world is part of those terms. "Our circles of interactions and mutual obligation, " he states at one point, "cannot be limited to our campsites, immediate neighborhoods, cities, nation-states, or even networks of international trading partners; they are truly and inescapably global" (Mitchell 2003: 207). Granted. Yet the further one goes from the campsite or immediate neighborhood, the less compelling the interaction is likely to become, and the more obligation is open to chance and whim. E-terms favor access and speed, rather than established patterns or shared grounds. E-mail works best when you want to make a quick contact, heedless of whatever might prevent or inhibit it — questions that have to be carefully negotiated in social life off-line.

So at variance with some realized manifestation of the social can e-terms be, in fact, that, in my own above case, they return even in an attempt to ignore them, for the worthy purpose (or so I thought) of trying to confirm a family member. (With some irony, I came away from the encounter convinced that my erstwhile family member would not even make a good e-mail correspondent.) Another example from my experience. A couple of years ago I read a letter in a professional journal from a man with whom I had once participated in a postdoctoral summer seminar. My fondest memories were of the table tennis games we used to play downstairs in a dorm. The man and I had never kept in touch afterwards. No particular reason why.

Enter e-mail. Indeed, a better example of the communicative ease of e-mail could not be imagined. I could just write the man, rather as I would knock on his door. So I did. He replied fondly, with various bits of news to take me across the years. So did his wife. But each wrote in a declarative mode, leaving little space for further exploration or comment. I responded with some words of thanks, feeling sure this would be the end of the contact, and so it was. E-mail suddenly enabled us to get back in touch. But just for a moment, only long enough to activate old feelings but not renew them. Life - to use one hopeless word for all the years between and all manner of circumstances, theirs as well as mine-simply had not favored the continuance of our relation, once the six weeks of that doctoral summer ended. Were we part of a "community" then? Perhaps. But if so, purely in terms of intellectual interests. Were we part of a "community" now? Only in the broad terms of belonging to the same disciplinary discourse.

What is a "community?" E-mail is in place today to provide one crucial determinant for how this question may be answered. But e-mail will not itself positively certify the answer, which instead will either come before some communicative manifestation of the technology or else after it. And once more, e-mail of any sort may well ultimately take place because the whole realm of the social has failed, especially in its ideal character as a community. (Mitchell is typical of those e-celebrants who proceed to recreate this character, without remarking on the failure, with such statements as the following: "The constants of my world are no longer provided by contiguous home turf; increasingly, my sense of continuity and belonging derives from being electronically networked to the widely scattered people and places I care about" [Mitchell 2003: 17].) Take a recent popular narrative of a utopian dreaming, Alex Garland's novel, The Beach (1998). At the end of the movie version, when the hero, Richard, is back in Bangkok, his island paradise gone, we last see him at a computer (in the novel it is a "word processor"), looking for a connection. 


\section{Body}

Question: where is the Internet at airports? Even in these cellular days, there are plenty of available "standing" telephones. But not many computer terminals. At the present time, a few of the priciest airlines for the longest flights (New York to Hong Kong or San Francisco to Singapore) do provide both First and Business class with e-mail, for a fee. Otherwise, nothing, although apparently airlines can outfit seats with laptop power outlets and PC data connections that provide roaming access to e-mail. Of course, broadband is coming, and soon. Meanwhile, why the delay to date, especially when personal seatback TV screens and live satellite 24-channel feeds (not to mention computer games and air phones) are becoming increasingly common? The answer may be a simple one: at airports and even in the air, e-mail becomes redundant.

Why do we e-mail? Because we are not there to communicate in person. The fact that we will be physically present, soon, explains, I believe, much of the reluctance of airlines to commit themselves to e-mail, which is presumed to function on the model of a telephone. Why call when you're going to be there? (Except to say you're on your way.) Just so, why e-mail, which is further presumed to function on the alternative model of a letter, which is only written when the correspondents are absent from each other? Why e-mail, when the word will shortly be made flesh? No need to choose between the difference between these two models, any more than there is between the difference within e-mail itself between its similarity to oral communication and to written communication.

To airlines, it is as if each similarity is true - and both models argue for the superfluousness of the technology, since each assumes communication either as a distant bodily relation or a completely absent one. The logic of the air travel, on the other hand, is wholly physical; the body will be transported through space, thereby bridging distance and relocating presence. A form of communication that effectively abstracts the body from space (and voids time) disturbs this logic. At least from the point of view of communication, better to dissolve the difference between "here" and "there" in a single keystroke, and effectively to do away with the cumbersomeness of the body completely. If this sort of rationale is disturbing to some-because the body loses its very privilege in space and time-it is exciting to others. There are lots of virtual ways of "having" a body, or rather of expressing one, now. As the airline industry begins to look for ways to incorporate them, it continues to be burdened by the fact that in the age of the Internet air travel is too slow.

There is a well-known New Yorker cartoon showing two dogs at respective computer terminals. One is delightedly saying to the other: "On the Internet, nobody knows you're a dog. " (Reprinted in Mitchell 1995: 6.) The joke is not merely that any identity is virtual, fake, possible. It is also that no body at all is necessary. In comparison to e-mail, previous communication technologies conveyed at least a physical trace — a hand, a voice. The typeface on the computer screen conveys none. Any body can write e-mail, disembodied. To this day, there are occasional stories of fifteen year-old girls who turn out to be forty year-old men, or vice versa, once the realm of the physical world is somehow re-entered, inexorably, from the realm of e-chat rooms. Is the on-line the moment when nobody knows who you are finally inseparable from the moment when somebody finds out who you are-and you want them to find out?

Of course, e-communication need not be so disembodied. Witness pornography, which some have maintained is equivalent to the Internet itself. On a more personal basis, the attachment of digital photographs or audio and video clips to e-mail restores the missing physical world, no less than subsequent telephone calls or meetings. The Internet, Agger writes, "opens up a new world of self-creation, storytelling, global communities, interactive instantaneity, and possibly even political organizing quite unknown in a slower-paced stage of modernity" (Agger 2004: 146). Quite true. But the Internet also opens up ways for a slower pace to re-absorb it, and re-ground the sheer provocation of nobody knowing who you are back to the constraints of everybody knowing because you abide in one place, at one time, and in one body.

Slavoj Zizek has an interesting argument about cyberspace. Countering those who maintain that we should never forget our bodies - the ultimate horizon of our existence, the foundation underlying our immersion in all possible virtual universes-he finds that "in cyberspace, we return to the bodily immediacy, but to an uncanny, virtual immediacy" (Zizek 2001: 54). Of what does it consist? "We learn that there never was" such a body-our bodily self-experience was always-already that of an imaginary constituted entity" (Zizek 2001: 55, his emphasis). Although Zizek does not say so, we could further speculate that it is precisely this fact that enables the place [ment] of the body in e-mail, at once an entity and the imaginary constitution of one, depending on the occasion.

Are most occasions still on a person-to-person scale? If so, to what extent does this scale appropriate the 
relation of bodily immediacy? After all, a short personal e-mail message may use cyberspace but scarcely inhabits it. On the other hand, if the communication is less personal (of an official nature, say, or to a whole group), to what extent does a larger scale necessarily either dispense with a bodily relation or else recreate it in a more imaginary fashion? Perhaps these are hapless, impossible questions. Never mind the conditions of individual e-mail in any particular instance. Consider merely the circumstances of the technology. Take Skype. As I write, Skype is the name of the most popular application of voice-over Internet protocol, a free software program which enables any two people (or conference callers up to five) to employ their computers to talk to each other.

Thereby, the computer becomes a telephone, e-mail once more makes available the body, and the virtual dimension of the Internet becomes actual. "Are we not more and more monads with no direct windows onto reality, "Zizek asks, " interacting alone with the PC screen, encountering only other virtual simulcra, and yet immersed more than ever in the global network, synchronously communicating with the entire globe" (Zizek 2001: 52). Well, not with Skype, or at least not in the same way as we are with Yahoo or Hotmail. While running, Skype literally appears on the computer screen in the form of a little window. The only ostensible thing that connects it to e-mail at all is that file transfers and instant text messages are allowed during each voice session.

Does Skype represent the e-future, enabling the body to suffer its fateful alienation (if we grant Žižek's argument) with more immediacy, if not illusions? Or is the future better represented by the situation of a man profiled in a recent New Yorker? He works in southern India and trains outsourced workers in computer use (requiring ever-new macros, databases, quality-control systems, information systems) for an American company. "Already, "he says at one point, "we are half of the time in New York, just our bodies are left behind" (Boo 2004: 65). The man has some regret. But he lives in the globalized future, where one day there will be neither religious bigotry nor a caste system but, it seems, time. "Soon we will really share only one time zone-or, really, there will be no time at all."

Did somebody say alienation? Its constitutive fact on-line is one thing; e-mail remains nothing if not basically a system of deferred interaction, or else why not make it real-time, if you can? And yet there are ranges or degrees of on-line alienation-some so wide and all-encompassing as to transpose alienation into severance of the body from its whole life-world. Donald Lowe is undoubtedly correct: "We can never know the actual lived body in the world" (Lowe 1995: 5). Yet a body whose reality does not intersect with language, body practices, and the social (Lowe's own particular favored coordinates) would not be a body in any sense we could recognize.

Much of the continued provocation of e-mail is that it does eradicate time. With good reason, Mitchell exclaims over wireless time as comprising "the electronic present continuous" (Mitchell 2003: 104). But the prospect would not be nearly so seductive in the first place if we did not abide in our own respective moments of time, continuous with our physical existence itself. Moreover, a technology, no matter how disembodied-or rather disembodying - that does not suffer a fall back into the temporal, conditional realm of the lived body would not be worth the provocation that e-mail continues to possess. The provocation is profound. "What if we could go all the way with shaking ourselves loose, "wonders Mitchell, shuck the last few atoms from our souls, and simply live on server farms somewhere" (Mitchell 2003: 167)? But the fall is no less decisive.

Mitchell himself fudges the issue, musing that the "server crash" of " mortality" need not be somehow implemented, since " by other means" (surgical procedures, all manner of downloading dematerialized information) we " are already asymptotically approaching that networked cyborg state" (Mitchell 2003: 168). In a real sense, Žižek's body-that-never-was reappears as Mitchell's cyborg body that now-from the time Neanderthal man picked up sticks and stone - at last is. But in an equally real sense, these bodies are hopelessly abstract. In particular, the body that e-mails rebukes them because it is fated to live out in actual social terms the circumstances that give rise to a fantasy of pure networking (Mitchell elsewhere refers to its access as "all very Platonic" [Mitchell 2003: 142]) in the first place. In order to illustrate how what we have at present are both the circumstances and the fantasy, let me relate a final story.

A friend once taught at the branch campus of a large Pennsylvania state university. She also belonged to a Latina feminist listserv. Issues of mutual interest were regularly discussed, along with professional news, conference notes, and so on. One day a member of the listserv became unusually belligerent. My friend was startled. It seemed everyone in the group suddenly become unsettled. She decided to write to the member, directly, offlist, and ask her to calm down. When she did so, she got an abusive response. Another attempt to mediate, still offlist, brought another belligerent reply. It seemed the woman (who now revealed herself for the first time as a lesbian 
as well as a Hispanic) accused my friend of "insulting me and my people. "

She made a final reply to the woman, wishing her and her people good luck, and declaring that she would no longer answer any of her messages. Result? The woman posted something of the off-list words to the listserv and at the same time sent copies of all of the personal correspondence to the dean of my friend's branch campus. To the dean, she demanded satisfaction for being insulted, since, after all, the university owned the server and therefore was ultimately responsible for its e-content. Rather than ignore the woman, the dean seized the opportunity to challenge my friend, who was in fact a critic of hers. The dean wrote an e-mail, mentioning the abusive woman's communication, and demanding to know if my friend was " for diversity. "

The technology "creates community? "In this instance it shattered its own and erupted destructively into another. The Internet sponsors a " decentered" self? Here, it was remorselessly centered, and poised to attack the selfhood of another. E-mail alienates the body? It depends not only on how the body is imagined but who gets to define its circumstances. Discussions of e-mail, it seems to me, routinely define the e-body from the position of [solitary] production. But it could just as easily be defined from the position of [collective] reception, where the body becomes inescapably less "virtual. "Such was the case here. My friend was shocked to see how quickly e-mail could loop from personal to social and back again, or how manifestly words could be suddenly made manifest in, or rather on, a body.

Finally, the body was hers. The dean's initial e-mail was, to her, the last in a long, intricate sequence of personal challenges, inequities, and insults. "Diversity?" It may be happier when it is virtual (and therefore discursive). Indeed, perhaps one reason it got to be so desirable is because the technology exists to keep it virtual-full of electric energy that can be transmitted on-line rather than material conditions that must be established offline. What my friend did is to treat her administration's acceptance of the absurd accuser as equivalent to being disowned. So she resigned. And she resigned in a manner that provides a sort of coda to this story, for she did not write a letter of resignation. Instead, she sent the dean a terse e-mail. The dean was almost instantaneously pleased to accept the resignation.

Would this exchange have happened so decisively at an earlier "technological" moment, not so many years ago, when letters would have had to be typed instead of messages posted? Hard to say. Did my friend afterwards regret her resignation, if only because she was able to convey it so fast-arguably, too fast? I do not think so. How fast is too fast, and to whom? Different people, different e-mails, and different relations to their respective bodies. What I would venture is that to resign a position over e-mail would feel to me to lend the technology too much authority, as if it and not me was performing the communication, while I looked on as if abstracted from my own body.

\section{Code}

On a recent trip to Brazil and Argentina I was struck by the difference between Internet cafes in each country. In Brazil, the computer terminals seem to be established on the model of video games, while in Argentina they are modeled on the basis of e-mail. Perhaps it was just the accident of the cafes I chanced to use in the respective countries, but in Brazil (primarily in one city, Curitiba), the users seemed mostly quite young, while in Argentina (solely in one city, Buenos Aires) they were much older. In any case, though, the clearest national difference had to do with the available technology itself: in Brazil, the Internet cafes feature computers, exclusively, while in Argentina the cafes include telephone booths.

How to explain this difference? In order to do so, one would have to examine the nature of telecommunications as it has developed in each country, as well as perhaps the national identity of each one (presumably more ludic in Brazil) as it can be recreated in terms of either Internet access or use. But how much does the comparison matter? Certainly not at all to the café user at any one time or space. As Mitchell writes, when he uses his cellphone or the OS on his laptop, " $[\mathrm{m}$ ] ostly I cannot tell whether [intermediating machine intelligence] is supplied by local devices, by remote servers, or by some combination of the two, and it doesn't matter-as long as there is capacity available somewhere, and the connections are sufficiently fast" (Mitchell 2003: 35).

And yet I believe the very question discloses much about Internet use insofar as e-mail is concerned. For all the discourse of globality, e-mail is not free of local conditions, and for all the fact of wireless connectivity, e-mail is still not free from national configurations. (The attempt by the People's Republic to monitor all servers in China 
being the most obvious example.) Moreover, for all the apparent subjective freedom, a system-a server of some sort-must be in pace in order to permit connection in the first place. This does not mean that subjectivity is governed by the conditions of access; even Hardt and Negri agree that because the Internet has no center, it is difficult for communication to be regulated or prohibited (Hardt and Negrl 2000: 299). What does it mean?

It means that all electronic communication is subject to code. In his earlier book, Mitchell defines code thus: "The rules governing any computer-constructed microworld-of a video game, your personal computer desktop, a word processor window, an automated teller machine, or a chat room on the networkare precisely and rigorously defined in the text of the program that constructs it on your screen." Therefore, he continues, we should ask the same questions about this "programmed polity" that Aristotle asked about city-states: "Is it just and humane. Does it protect our privacy, our property and our freedoms? Does it constrain us unnecessarily or does it allow us to act as we may wish" (Mitchell 1995: 111)? Elsewhere, having characterized code as an arcane text, typically accessible by only a few "high priests," he repeats his cautions: "Who shall write the softwear that increasingly structures our daily lives? What shall that softwear allow and proscribe. Who shall be privileged by it and who marginalized? How shall the writers of the rules be answerable" (Mitchell 1995: 112)?

These questions are notably absent in Mitchell's latest volume. In both, code is stated to constitute the law. But in $\mathrm{Me}++$, Mitchell exhibits no desire to interrogate the fact, as he does earlier. What has happened during the intervening eight years? Two developments in particular. First, code has evolved-become more "footloose," more "mobile," and no longer an affair of floppy disks or punch cards. As Mitchell summarizes, "Dematerialized and radically mobilized code has become allied with the memory and computation capability now embedded in gadgets and machines of all kinds and with the increasingly comprehensive networking of these devices" (Mitchell 2003: 90). No wonder the enticing prospect of "the full Foucault treatment" (with respect to the recognition of code's power implicit in the Y2K scare of 1999) is relegated to a footnote, and then handled over to the reader as an "exercise" (Mitchell 2003: 232). By 2003, Mitchell has ceased to believe in the power of such a treatment, which surely motivated his political concerns eight years ago. Today, code is simply "everywhere." Its law is implacable.

The second development directly follows from the first: we have become coded. Code not only takes up residence in our networks, our software programs, our computers. (Destructively in the case of viruses.) Code takes up residence in us-in our bodies, our daily lives, our political choices. We have become inseparableinconceivable-from our electronic extensions. In a real sense, Mitchell's above concerns about code in 1995 have been rendered supererogatory by 2003. Code evolved more quickly than he could have imagined. Nobody writes code; increasingly it merely appears as written. Moreover, one worries less about who is marginalized by code; more and more people are simply enabled by it, even whether or not they have computers or do e-mail. If there are writers of the rules, they are answerable to no one-and we do not care, since all we want to do is to log on or enjoy a secure connection.

At one point in Don DeLillo's latest novel, Cosmopolis, a woman makes the following glazed pronouncement, while regarding the various digital displays on screens in a limo: "People will not die. Isn't this the creed of the new culture? People will be absorbed in streams of information...Computers will die. They're dying in their present form. They're just about dead as distinct units. A box, a screen, a keyboard. They're melting into the texture of everyday life" (DeLillo 2003: 104). Cosmopolis provides a kind of fictionalized reading of Mitchell, from the lofty perspective of its protagonist, Eric Packer, a billionaire assets manager. Why a billionaire? In order for the text to test the possibility of standing outside the System (whether It is defined as Capitalism, the Internet, or something else). The array of "visual display units" testify to Its ubiquity, giving "data" so much pulsation as to be almost formless. "Hand-held space, "we read, is "almost finished now. The context was nearly touchless. He could talk most systems into operation or wave a hand at a screen and make it go blank" (DeLillo 2003: 13).

And yet, no matter how sovereignly connected (the sovereignty including its own resistance, and therefore foreclosing some Foucault-driven critique), Packer remains lodged in his body. He has sex twice during the narrative, as well as a digital prostate exam, and the catalyst of the narrative is his desire to get a haircut across town. The visual display units in the limo become a species of alternate flesh, the exterior form of electronic energy beyond not only form but content, purpose, and certainly code. "We are not witnessing the flow of information so much as pure spectacle, "Packer muses, "or information made sacred, ritually unreadable. The small monitors of the office, home and car become a kind of idolatry here, where crowds might gather in astonishment" (DeLillo 2003: 80). We can take e-mail as representative of activity on the scale of one of these monitors. (Cosmopolis disdains to mention e-mail specifically.) In comparison to the data stream, e-mail seems fleshy and context- 
bound.

Worse, e-mail appears hopelessly subjective. Its source, if not extension, is personal. It continues to flow beneath visibility -as we understand anew each time an instance of e-mail does accidentally become visible. As I write, for example, an e-mail message by a Wall Street Journal reporter working in Iraq has created something of a scandal, once it "made its way" to the Internet. (Reports do not say how the transmission occurred.) The reporter apparently intended the message for friends only. But the description of her own working conditions-in which she cannot leave her hotel room for fear of being killed-is felt to be at least as compelling as her more "objective" social and political reports on the chaos into which Baghdad has fallen. Presumably at least some of these reports have been conveyed electronically. What counts as e-mail, though, is the private register, and its subjective dimension.

But this, in turn, appears scarcely worth accounting for, particularly in the new mobile universe of dying computers and nomadic code. The least we can say is that the moment of "idolatry" is over for e-mail. Different than a letter or a telephone call, it is now nonetheless merely another available form of communication, about which we can afford to be incurious. "Obviously, "Mitchell remarks, "it is possible, in principle, to precisely track things through networks, but in practice we rarely care about this. We experience networks at their interfaces, and only worry about the plumbing behind the interfaces when something goes wrong" (Mitchell 2003: 15). "E-mail" has emerged as the name of the "plumbing, "the network that plumbing makes possible, the peculiar program that permits access to the network, and the particular kind of personal communication that the program, the network, and the plumbing afford.

In effect, therefore, e-mail has been absorbed into the "data stream" so thoroughly that the fact your program is subject to code, like all else, need be recalled only if you happen to forget your password. Another item from the day's newspaper: instant messaging is no more merely an affair of the desktop-now it has gone mobile and is increasingly being sent from cellphones. So is a discussion of e-mail at the present time obliged to try to distinguish instant messaging from e-mail? (Or even cellphones from computers?) What about the social and political effects of yet another new feature of electronic computation? Meanwhile, again, the technology proceeds, it seems, with a connective momentum of its own; as Mitchell notes: " [1] aptops are beginning to talk wirelessly to video projectors, projectors and cameras to printers, telephones to speaker systems, video cameras to monitors . ... and so on" (Mitchell 2003: 164).

The technology comprises all so much "talk," precisely. E-mail? Merely one register for the relay. We can accent the experience of subjective freedom e-mail affords on the individual level. But only, it seems to me, if we emphasize how both the freedom and the level are won by virtue of a code that cannot itself be experienced. The closest we get to experiencing it are those moments when the wondrous immateriality and immanence of electronic connection itself appears suddenly in some outer form - the Internet café you need to find when abroad so you can e-mail at all, or the workplace you realize is utterly fixed because the e-mail you took to be private was in fact being backed up all along. (As Mitchell notes: "Whenever you send an email ... you create copies on multiple servers, and those servers are automatically backed up at regular intervals" (Mitchell 2003: 183). And then at these moments what can we conclude? Let me relate a final story to bear on the final question.

Once he went away to graduate school, a former student and I got to know each other better through e-mail than we ever did in life. Nay, our daily e-mails to each other eventually became as much a part of our respective lives as the morning's coffee or the afternoon's classes. We attached various items from the web, we exchanged papers, but mostly we just talked, often in the form of long posts about literature read, movies seen, convictions shared, and ideas pondered. Our e-mail continued in this manner for some years, through his eventual completion of a doctorate, a first job, and then a second, which coincided with my early retirement from my own position, and then four-year contract with a university in Japan. Bill's second job was with a huge, Internet-based business.

Early on, he told me of some sort of friction with a supervisor. I do not remember exactly what. Perhaps it did not really matter. This new corporate culture was rife with power, all of it intense, elusive, combative. In order to prove it, one day at a large employee meeting area the supervisor suddenly pressed a few buttons on a nearby laptop and flashed a page's worth of Bill's recent e-mails on an overhead screen for all to see. Bill was especially embarrassed to read the emails to his wife, full of private terms of affection as well as reference about the business. His fellow workers were all very amused at this demonstration. It was as if e-mail was suddenly revealed not to be, well, e-mail, but instead a public rather than private form of communication, written rather than oral, and fixed rather than fluid. 
What to conclude? In our immediate experience of e-mail, few of us ever attain, or perhaps imagine, such a moment of visibility. And yet it seems to me that we had better proceed as if this moment is ceaselessly available, not to each one of us but instead to the systems in which our e-mail is programmed, transmitted, and stored. In each case, code has been written. Code remains the law. No more than Hardt and Negri, I want to waiver on the crucial matter of what their idiom would characterize as its "sovereignty. "My own immediate experience of e-mail abides as free and subjective. And yet I know not only that it is bounded but constructed according to certain laws that I neither know or care to know, by means of which is attained what Hardt and Negri term "the circulating society of the spectacle. "They are speaking of ether, or the third medium of imperial control (the first two being the bomb and money), in which-in part-sovereignty is articulated through communication systems. How? By "attack[ing] the very possibility of linking an order to a space" and "impos[ing] a continuous and complete circulation of signs" (Hardt and Negri 2000: 347).

What to do once an extreme limit of the dissolution between order and space is reached? I take this limit to be continuous with what Mitchell so devoutly imagines as the completely wireless (and therefore connected) globe. Hardt and Negri conclude as follows: "At this point we cannot conceive this relationship except in another space [their italics], an elsewhere that cannot in principle be contained in the articulation of sovereign acts" (Hardt and Negri 2000: 347). What this means for e-mail is simple: the need for another space becomes manifest in another account. Or even another, and another. People who have several e-mail addresses are not only acting out the plenitude of virtual selfhood that [cyber]space makes possible. They are performing the circulating society of the spectacle; no matter that there are few sovereign personages (of whom we can take DeLillo's Packer to be one) in position to comprehend it. Moreover, where to locate an impossible space where some need for sovereignty can at least be performed, and perhaps in addition where some reconnection between space and order can be made?

In the case of my former student-with whom, years ago, through e-mail it would have been a rare pleasure to explore this last point at some length-the process of the dissolution between order and space had grown too advanced. Not only were we now more physically distant. His new job imposed enormous demands-all of them having to do with e-mail. He took out a Yahoo account, possibly another, and then wrote for awhile from still another address that seemed to be that of his business. But the actual can only collapse so much into the virtual, and fixed space can only dissolve so far into cyberspace. Slowly, inexorably, the two of us ceased to communicate. To the end, we retained a connection: our respective addresses. But a connection is not the same thing as a relation. There is not yet code for a relation, and, it appears, still only a limited amount of space.

\section{References}

Agger, Ben. 2004. The Virtual Self. A Contemporary Sociology. Malden, MA: Blackwell.

Barksdale, James. 1998. "Communications Technology in Dynamic Organizational Communities. "In Frances Hasselbem, Ed. Community: 93-100.

Boo, Katherine. 2004. "Letter from India. “ The New Yorker. July 5, 2004: 54-69.

Ch'ien, Evelyn Nien-ming. 2004. Weird English. Cambridge: Harvard University Press.

DeLillo, Don. 2003. Cosmopolis. New York: Scribner.

Garland, Alex. 1998. The Beach. New York: Riverhead Books.

Hardt, Michael and Antonio Negri. 2000. Empire. Cambridge:Harvard University Press.
Hesselbem, Frances, ed.1998. Community of the Future. New York: Jossey-Bass.

Lowe, Donald. 1995. The Body in Late-Capitalist USA. Durham: Duke University Press.

Mitchell, William J. City of Bits. 1995. Space, Place, and the Infobahn. Cambridge: MIT Press.

-.-- 2003. Me++. The Cyborg Self and the Networked City. Cambridge: MIT Press.

Rheingold, Howard. 1998. "Virtual Communities. "In Hasselbem, Community: 115-22.

Zizek, Slajov. 2001. On Belief. New York: Routledge. 